\title{
Using Fenton Oxidation Method to Advanced Treatment of Landfill Leachate
}

\author{
Gao Yanjiao ${ }^{1}$, Huang Runzhu ${ }^{1, *}$ and Song Tiehong ${ }^{2}$ \\ ${ }^{I}$ School of Civil and Architectural Engineering, Liaoning University of Technology, Jinzhou, Liaoning, 121001, P.R. \\ China \\ ${ }^{2}$ Key Laboratory of Songliao Aquatic Environment, Ministry of Education, Jilin Jianzhu University, Changchun, \\ Jilin, 130118, P.R. China
}

\begin{abstract}
Hydrogen peroxide and ferrous sulfate were used to advanced treatment of landfill leachate effluent from biochemical tanks. Some influences on removing COD and chroma including the $\mathrm{pH}$ value of solution, the dosage of ferrous sulfate, the dosage of hydrogen peroxide and reaction time were investigated. The test results showed that for removal of COD and chroma the optimal $\mathrm{pH}$ was 3.0, the best ferrous sulfate and hydrogen peroxide dosage was $1500 \mathrm{mg} / \mathrm{L}, 20 \mathrm{~mL} / \mathrm{L}$ respectively, and the optimal reaction time was $60 \mathrm{~min}$. Under optimal conditions, COD and chroma removal rate could reach $79.7 \%$ and $95.2 \%$ respectively.
\end{abstract}

Keywords: Ferrous sulfate, hydrogen peroxide, landfill leachate.

\section{INTRODUCTION}

This work involves the subsequent processing technology of landfill leachate effluent from biochemical tanks. Common landfill leachate treatment technologies are combination of biological methods and chemical methods [1]. Biological methods can be anaerobic-aerobic combined methods, but in an anaerobic-aerobic process, some materials are difficult to biologically degradation, and BOD can't meet discharging standard. The oxidation system of Fenton reagent is consisted of hydrogen peroxide and catalyst ferrous ions. Hydrogen peroxide produces two kinds of active hydroxyl radicals under the effect of catalyst ferrous ions. Ferrous ions can trigger and spread free radical chain reaction, and accelerate the oxidation rate of organic matter. Fenton reagent can oxidize organic compounds which have benzene, hydroxy, substituent group such as carboxyl group and sulfo group [2]. The advantages of Fenton oxidation are quickly reaction, moderate temperature and pressure, and no secondary pollution. In recent years, some scholars used Fenton reagent to treat landfill leachate effluent, due to different garbage sources and landfills, the leachate treating methods are different. Fenton method treating landfill leachate effluent has not used in a large scale. In this study, landfill leachate effluent from biochemical process was treated by Fenton reagent, and the effects of solution $\mathrm{pH}$ value, the dosage of ferrous sulfate, the dosage of hydrogen peroxide and reaction time on effluent COD and chroma removal were investigated [3].

*Address correspondence to this author at the School of Civil and Architectural Engineering, Liaoning University of Technology, Jinzhou, Liaoning, 121001, P.R. China Tel: 13332189257;

E- mail: gstiehong@163.com

\section{EXPERIMENTAL}

The COD of landfill leachate effluent from biochemical process was $925.3 \mathrm{mg} / \mathrm{L}$, and the BOD was $342.8 \mathrm{mg} / \mathrm{L}$, the solution $\mathrm{pH}$ value was 8.01 and chroma was 650 . In this experiment $1000 \mathrm{ml}$ beakers were used as reaction devices, which were placed on six league blender with heating chassis for chemical reaction, and agitator certain rotational speed could be adjusted. Reaction reagent were ferrous sulfate (chemical pure) and hydrogen peroxide (industrial, content was $30 \%) . \mathrm{H}_{2} \mathrm{SO}_{4}$ and $\mathrm{NaOH}$ were used to adjusted $\mathrm{pH}$ value. After a period of reaction time, the beakers were removed and settled for 45 minutes. Water effluent COD, chroma and $\mathrm{pH}$ value were determined [4].

\section{RESULTS AND DISCUSSION}

\subsection{The Effects of Initial pH Value on Effluent COD and Chroma Removal}

The initial $\mathrm{pH}$ value of landfill leachate effluent has important influence on efficiency of Fenton reaction. Different $\mathrm{pH}$ value made different iron form in solution. $\mathrm{Fe}^{2+}$ could catalyze $\mathrm{H}_{2} \mathrm{O}_{2}$ and produce $\mathrm{OH}$ under acid condition, but could not play a catalytic under neutral and alkalinity conditions. The researchers generally agreed that when $\mathrm{pH}$ value was $2 \sim 4$, wastewater treatment effect was better [5].

In this experiment initial $\mathrm{pH}$ were adjusted from 2.0 to 4.5 , ferrous sulfate was $500 \mathrm{mg} / \mathrm{L}$ and hydrogen peroxide was $20 \mathrm{~mL} / \mathrm{L}$, mixing reaction time was 30 minutes, and settled time was 45 minutes. The effluent COD and chroma results were shown in Figs. (1 and $\mathbf{2}$ ). 


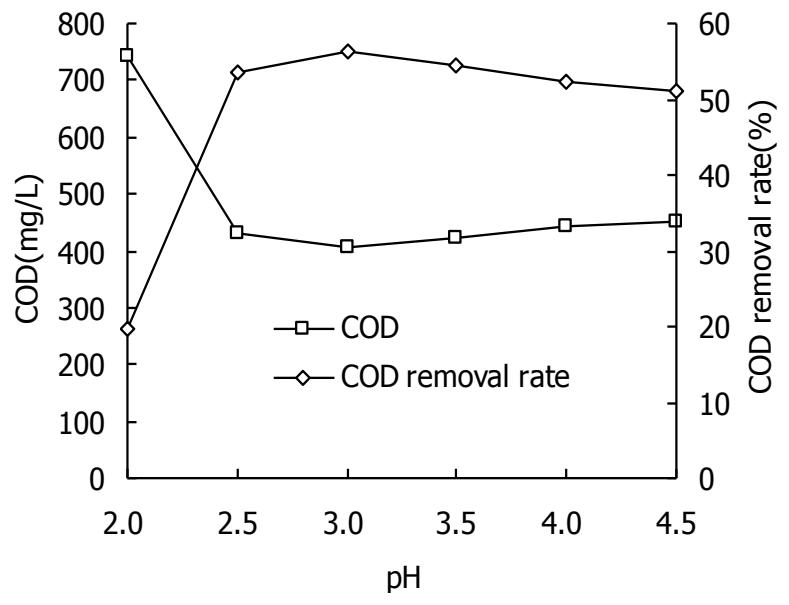

Fig. (1). The effect of $\mathrm{pH}$ value on COD removal.

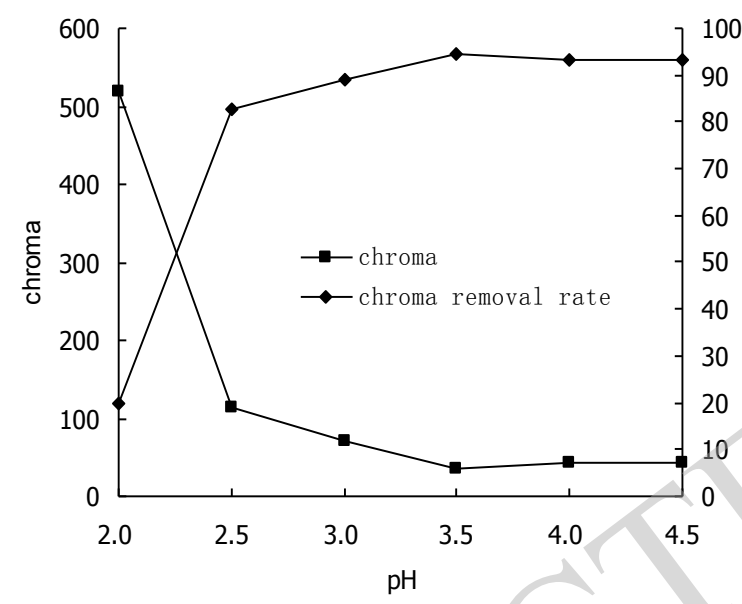

Fig. (2). The effect of $\mathrm{pH}$ value on chroma removal.

As shown in Fig. (1), when the solution $\mathrm{pH}$ value increased from 2.0 to 3.0 ,COD decreased soon after reaction, $\mathrm{COD}$ removal rate increased from $19.6 \%$ to $56.2 \%$. When $\mathrm{pH}$ value increased from 3.0 to $4.0, \mathrm{COD}$ increasing became slowly, and COD removal rate dropped from $56.2 \%$ to $51.1 \%$. Fig. (1) showed that when $\mathrm{pH}$ value was 3.0, removal efficiency was a point, and the $\mathrm{pH}$ value of 2.0-3.0 for COD removal efficiency were the best. This suggested that too high or too low $\mathrm{pH}$ value were undesirable. When $\mathrm{pH}$ value was less than $2, \mathrm{Fe}^{3+}$ could not be successfully reduced to $\mathrm{Fe}^{2+}$, catalytic reaction was inhibited, thereby the hydroxyl radical generation became slow, and the oxidation ability was reduced. When the $\mathrm{pH}$ value was greater than 3 , The stability of hydrogen peroxide was decreased, and Hydrogen peroxide decomposition speed was accelerated, and inhibit the hydroxyl radical production was inhibited, thus the treatment effect was affected.

The effects of initial $\mathrm{pH}$ value on effluent COD and chroma removal were shown in Fig. (2). When the solution $\mathrm{pH}$ value increased from 2.0 to 3.0 , chroma decreased soon after reaction, chroma removal rate increased from $20.0 \%$ to $94.7 \%$. With the $\mathrm{pH}$ value increasing from 3.5 to 4.5 , the removal rate of the chroma had little change after reaction. This showed that for the chroma removal, the best $\mathrm{pH}$ value was 3.5. From Fig. (1), for the removal of COD, $\mathrm{pH}$ value of 3 was appropriate. Therefore, the optimum $\mathrm{pH}$ value was considered as 3.0.

\subsection{The Effects of $\mathrm{FeSO}_{4}$ Dosage on Effluent COD and Chroma Removal}

In Fenton reactions, $\mathrm{Fe}^{2+}$ used as a catalyst could catalyze $\mathrm{H}_{2} \mathrm{O}_{2}$, produce hydroxyl radical, and decomposed pollutants. The less $\mathrm{Fe}^{2+}$, the less radical and the lower speed, the catalytic process was restrained. Excessive $\mathrm{Fe}^{2+}$ could reduced $\mathrm{H}_{2} \mathrm{O}_{2} \cdot \mathrm{Fe}^{2+}$ was oxidized as ferric ion and made solution chroma increasing.

In Fig. (3), with the $\mathrm{FeSO}_{4}$ dosage increased from 500 $\mathrm{mg} / \mathrm{L}$ to $1500 \mathrm{mg} / \mathrm{L}$, COD removal rate increased from $37.2 \%$ to $78.2 \%$,then with $\mathrm{FeSO}_{4}$ dosage increased to 2500 $\mathrm{mg} / \mathrm{L}$, COD removal rate drop from $78.2 \%$ to $65.5 \%$ .Therefore, the amount of $\mathrm{FeSO}_{4}$ was not the more the better.Because the excessive $\mathrm{Fe}^{2+}$ will reduced of $\mathrm{H}_{2} \mathrm{O}_{2}$ and affect the removal effect of COD. For the COD removal, the best $\mathrm{FeSO}_{4}$ dosage was $1500 \mathrm{mg} / \mathrm{L}$.

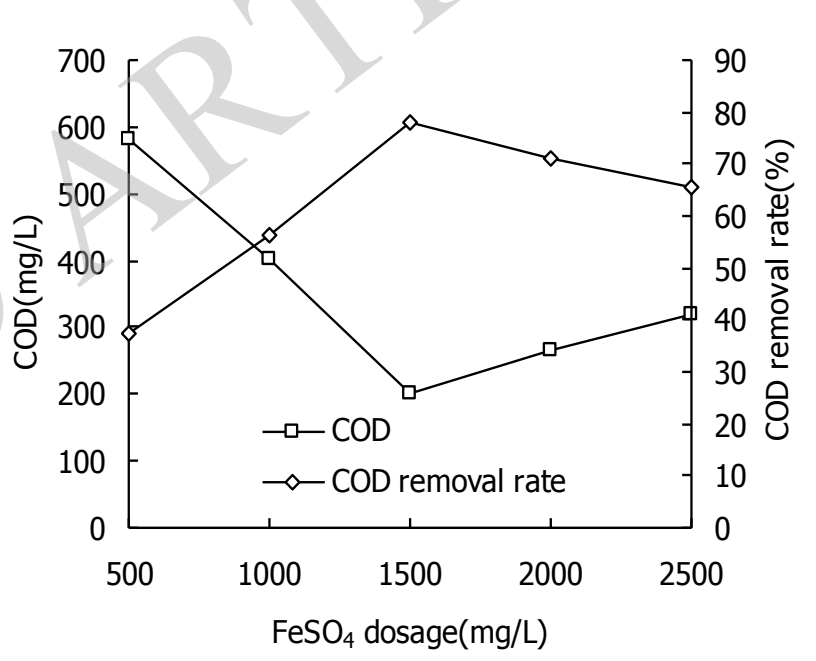

Fig. (3). The effect of $\mathrm{FeSO}_{4}$ dosage on COD removal.

In Fig. (4), with the $\mathrm{FeSO}_{4}$ dosage increased from 500 $\mathrm{mg} / \mathrm{L}$ to $1500 \mathrm{mg} / \mathrm{L}$, chroma was declined, chroma removal rate increased from $72.1 \%$ to $90.3 \%$, then with $\mathrm{FeSO}_{4}$ dosage increased to $2500 \mathrm{mg} / \mathrm{L}$, COD removal rate dropped from $90.3 \%$ to $60.4 \%$. Therefore, $\mathrm{FeSO}_{4}$ dosage was not the more the better for chroma removal. Because excessive $\mathrm{Fe}^{2+}$ could oxidize $\mathrm{Fe}^{2+}$ to $\mathrm{Fe}^{3+}$ and increased the chroma of the solution. The experiment testified the best $\mathrm{FeSO}_{4}$ dosage was $1500 \mathrm{mg} / \mathrm{L}$.

\subsection{The Effects of $\mathrm{H}_{2} \mathrm{O}_{2}$ Dosage on Effluent COD and Chroma Removal}

The mechanism of Fenton reagent removing organic contaminants were that hydrogen peroxide produced two kinds of active hydroxyl radicals that trigger and spread free radical chain reaction, and accelerate the oxidation rate of organic matter and reduced substances [6]. $\mathrm{H}_{2} \mathrm{O}_{2}$ dosage had important influence on $\mathrm{COD}$ and chroma removal. $\mathrm{H}_{2} \mathrm{O}_{2}$ dosage also involved in the cost of water treatment. Under 
the conditions of $\mathrm{pH} 3.0$, strring time 30 minutes , $\mathrm{FeSO}_{4}$ $1500 \mathrm{mg} / \mathrm{L}$, hydrogen peroxide quantity from $10 \mathrm{~mL} / \mathrm{L}-50$ $\mathrm{mL} / \mathrm{L}$, the experiment results were shown in Figs. (5 and $\mathbf{6}$ ).

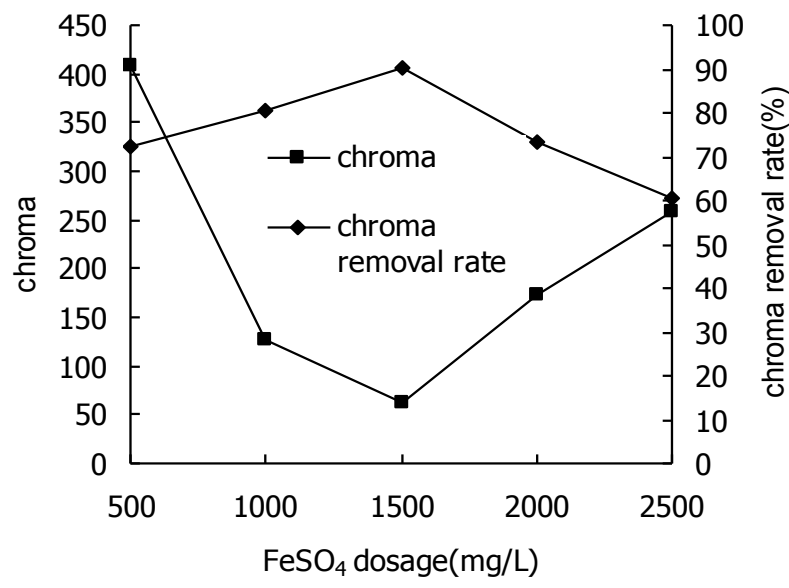

Fig. (4). The effect of $\mathrm{FeSO}_{4}$ dosage on chroma removal.

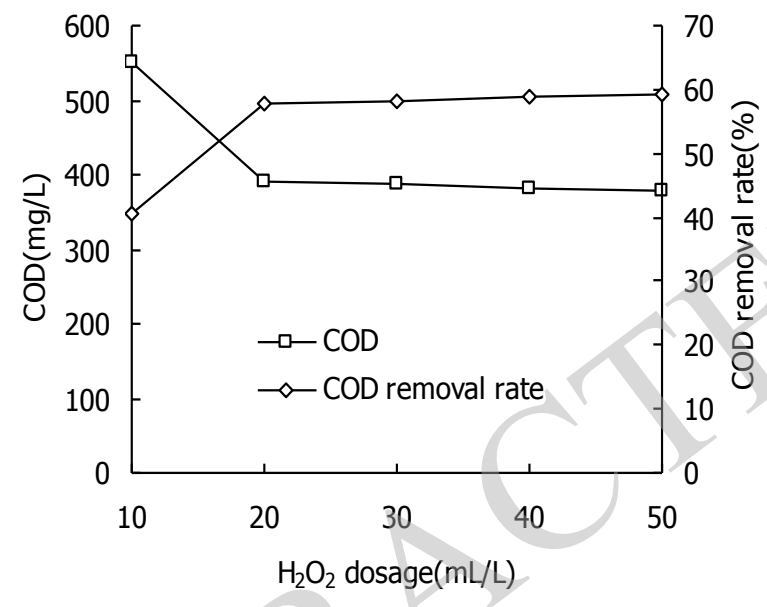

Fig. (5). The effect of hydrogen peroxide dosage on COD removal.

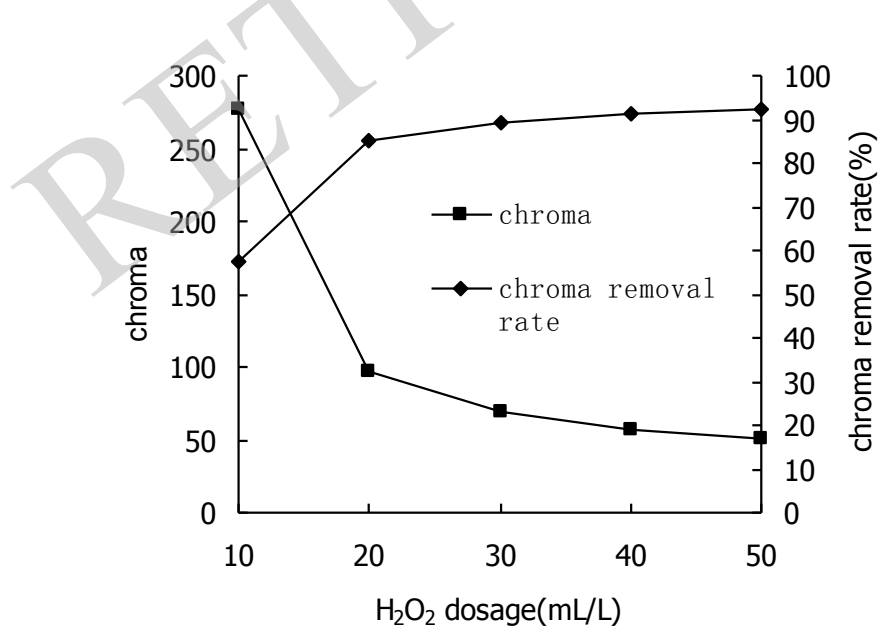

Fig. (6). The effect of hydrogen peroxide dosage on chroma removal.
In Fig. (5), the hydrogen peroxide dosage increased from $10 \mathrm{~mL} / \mathrm{L}$ to $20 \mathrm{~mL} / \mathrm{L}$, COD was decreased soon, COD removal rate increased from $40.5 \%$ to $57.8 \%$, then with the hydrogen peroxide dosage increased to $50 \mathrm{~mL} / \mathrm{L}$, COD removal rate increased from $57.8 \%$ to $59.1 \%$.Although the hydrogen peroxide dosage increased, COD removal increasing became slow. This means that the hydrogen peroxide as a oxidant was not the more the better. When hydrogen peroxide increased to a certain extent, hydrogen peroxide decomposed and released oxygen to inhibit the COD removal efficiency [7]. This experiment testified the best hydrogen peroxide dosage was $20 \mathrm{~mL} / \mathrm{L}$ for COD removal.

In Fig. (6), when the hydrogen peroxide dosage increased from $10 \mathrm{~mL} / \mathrm{L}$ to $20 \mathrm{~mL} / \mathrm{L}$, chroma was declined, and chroma removal rate increased from $57.5 \%$ to $85.2 \%$. Then with hydrogen peroxide dosage increased to $50 \mathrm{~mL} / \mathrm{L}$, COD removal rate increased from $85.2 \%$ to $92.1 \%$. Although the hydrogen peroxide dosage increased, chroma removal increasing became slow. This testified that the hydrogen peroxide as a oxidant was not the more the better. Because of hydrogen peroxide increased to a certain extent, hydrogen peroxide was decomposed and released oxygen to inhibit the chroma removal efficiency. This experiment testified the best hydrogen peroxide dosage also was $20 \mathrm{~mL} / \mathrm{L}$ for chroma removal.

\subsection{The Effect of Reaction Time on COD and Chroma Removal}

Fenton reagent for degradation of organic matter mainly relied on hydrogen peroxide to produce hydroxyl radicals with organic chemical reaction, the generation rate of hydroxyl and the reaction rate of the organic matter directly determined the reaction time required. Reaction time was very important for wastewater treatment $[8,9]$. Under the condition of $\mathrm{pH} 3.0, \mathrm{FeSO}_{4} 1500 \mathrm{mg} / \mathrm{L}$, hydrogen peroxide $20 \mathrm{~mL} / \mathrm{L}$, the results were shown in Figs. (7 and 8).

In Fig. (7), with reaction time increased from 30 minutes to 150 minutes, COD decreased, COD removal rate increased from $57.8 \%$ to $85.3 \%$. When the reaction time reached 60 minutes, removal rate reached $79.7 \%$. Therefore, the best reaction time was 60 minutes from the perspective of cost.

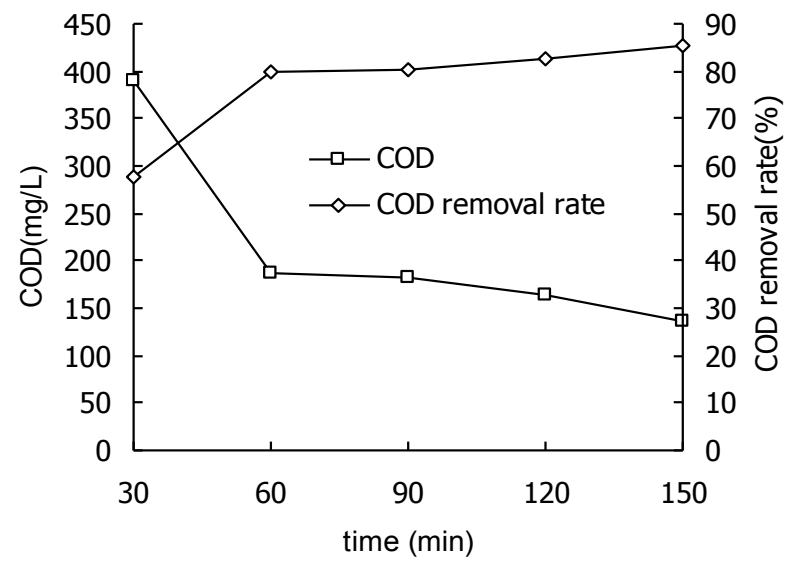

Fig. (7). The effect of reaction time on COD removal. 
In Fig. (8), With reaction time increased from 30 minutes to 60 minutes, chroma decreased, chroma removal rate increased from $72.1 \%$ to $95.2 \%$, then increasing the reaction time ,removal rate of chroma had little change in a stable state. This experiment testified the best reaction time was 60 minutes for chroma [10].

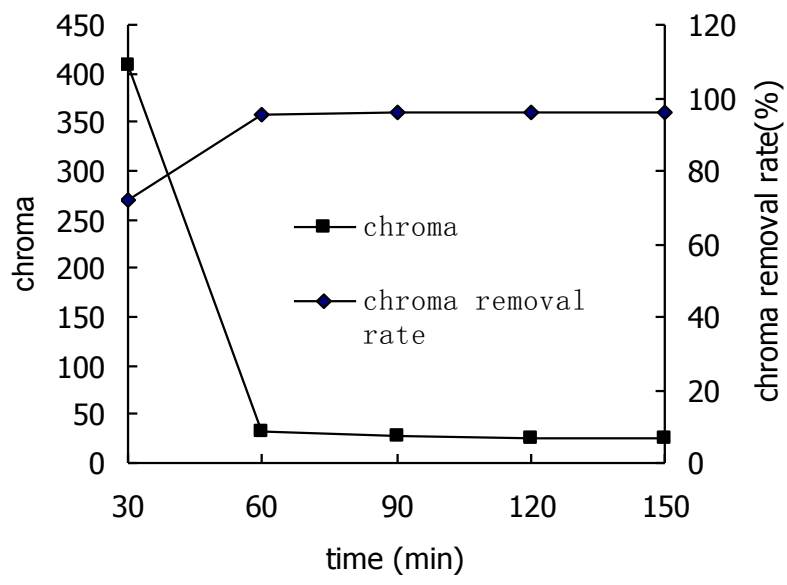

Fig. (8). The effect of reaction time on chroma removal.

\section{CONCLUSION}

(1) The $\mathrm{pH}$ value of landfill leachate effluent had important influence on Fenton reagent oxidation. $\mathrm{pH}$ value was too high or too low, the COD removal decreased, and the best $\mathrm{pH}$ value was 3.0.

(2) In Fenton, $\mathrm{Fe}^{2+}$ as a catalyst, the dosage have important influence on reaction. Test showed that excessive $\mathrm{Fe}^{2+}$ was not good, and the best $\mathrm{FeSO}_{4}$ dosage was $1500 \mathrm{mg} / \mathrm{L}$ in the experiments.

(3) $\mathrm{H}_{2} \mathrm{O}_{2}$ as an oxidant whose dosage determined the reaction effect and the best hydrogen peroxide was 20 $\mathrm{mL} / \mathrm{L}$.

(4) Reaction time was also one of the important factors on reaction effects. When reaction time was 60 minutes, Fenton reagent can achieve good effect.

Fenton reagent consisted of $\mathrm{H}_{2} \mathrm{O}_{2}$ and $\mathrm{FeSO}_{4}$ could effectively treat landfill leachate effluent. The best $\mathrm{pH}$ value was 3.0, the best dosage of ferrous sulfate was $1500 \mathrm{mg} / \mathrm{L}$, the best dosage of hydrogen peroxide was
$20 \mathrm{~mL} / \mathrm{L}$ and the best reaction time was 60 minutes.Under the best conditions, COD removal rate could reach $79.7 \%$ and the chroma removal rate could reach $95.2 \%$.

\section{CONFLICT OF INTEREST}

The authors confirm that this article content has no conflict of interest.

\section{ACKNOWLEDGEMENTS}

Declared none.

\section{REFERENCES}

[1] Y. Deng, and J.D. Englehardt, "Treatment of landfill leachate by the Fenton process", Water Research, vol. 40, pp. 3683-3694, 2006.

[2] Y. Deng, "Physical and oxidative removal of organics during Fenton treatment of mature municipal landfill leachate", Journal of Hazardous Materials, vol. 146, pp. 334-340, 2007.

[3] S. Renou, J.G. Givaudan, S. Poulain, F. Dirassouyan, and P. Moulin, "Landfill leachate treatment: Review and opportunity", Journal of Hazardous Materials, vol. 150, pp. 468-493, 2008.

[4] Y.W. Kang, and K.Y. Hwang, "Effects of reaction conditions on the oxidation efficiency in the Fenton process", Water Research, vol. 34, pp. 2786-2790, 2000.

[5] J.S. Guo, A.A. Abbas, Y.P. Chen, Z.P. Liu, F. Fang, and P. Chen, "Treatment of landfill leachate using a combined stripping, Fenton, SBR, and coagulation process", Journal of Hazardous Materials, vol. 178 , pp. 699-705, 2010.

[6] H. Li, S. Zhou, Y. Sun, P. Feng, and J. Li, "Advanced treatment of landfill leachate by a new combination process in a full-scale plant", Journal of Hazardous Materials, vol. 172, pp. 408-415, 2009.

[7] A. Goi, Y. Veressinina, and M. Trapido, "Fenton process for landfill leachate treatment: evaluation of biodegradability and toxicity", Journal of Environmental Engineering, vol.136, pp. 46$53,2009$.

[8] S. Mohajeri, H.A. Aziz, M.H. Isa, M.A. Zahed, and M.N. Adlan, "Statistical optimization of process parameters for landfill leachate treatment using electro-Fenton technique", Journal of Hazardous Materials, vol.176, pp. 749-758, 2010.

[9] H. Zhang, H.J. Choi, P. Canazo, and C.P. Huang, "Multivariate approach to the Fenton process for the treatment of landfill leachate", Journal of Hazardous Materials, vol. 176, pp. 1306$1312,2009$.

[10] Y. Wu, S. Zhou, F. Qin, H. Peng, Y. Lai, and Y. Lin, "Removal of humic substances from landfill leachate by Fenton oxidation and coagulation", Process Safety and Environmental Protection, vol. 88 , pp. 276-284, 2010. 